\title{
GOSTO, IDEOLOGIA E CONSUMO ALIMENTAR: PRÁTICAS E MUDANÇAS DISCURSIVAS SOBRE PLANTAS ALIMENTÍCIAS NÃO CONVENCIONAIS - PANC
}

\author{
Tasting, Ideology and Food Consumption: practices and discursive changes about non- \\ conventional food plants
}

Antonio Hélio Junqueira ${ }^{1}$

Universidade Anhembi Morumbi (UAM)

Elaine Aparecida Perline ${ }^{2}$

Universidade Anhembi Morumbi (UAM)

\begin{abstract}
RESUMO
A pesquisa explora o fenômeno da intensa midiatização das chamadas Plantas Alimentícias Não Convencionais (PANC) no cenário da gastronomia brasileira contemporânea, visando apontar e discutir movimentos de mudança nas práticas discursivas relacionadas à produção e consumo desses vegetais. Para tanto, elegeu um corpus constituído por um conjunto amplo e diversificado de textos midiáticos de diferentes gêneros de discurso produzidos, postos em circulação e consumidos no país, entre os anos de 2014 e 2018, sobre o qual foram aplicados os princípios teórico-metodológicos da Análise do Discurso em seus desdobramentos e conexões com a mudança social. Foi possível observar alterações significativas tanto na lexicalização dos termos relacionados a essas plantas, quanto na constituição de novas formações discursivas transformadoras das ordens sociais do discurso, em luta pela instituição de novas hegemonias alimentares.
\end{abstract}

Palavras-chave: Análise do Discurso. Prática discursiva. Mudança social. Ideologia e hegemonia. Identidade alimentar.

\begin{abstract}
The research explores the phenomenon of the intense mediatization of the Non-Conventional Food Plants $(P A N C)$ in the scenario of contemporary Brazilian gastronomy, aiming at pointing out and discussing changes in the discursive practices related to the production and consumption of these vegetables. In order to do so, it chose a corpus consisting of a broad and diversified set of media texts of different discourse genres produced, put into circulation and consumed in the country, between 2014 and 2018, on which the theoreticalmethodological principles of Discourse Analysis in its unfolding and connections with social change. It was possible to observe significant changes both in the lexicalization of the terms related to these plants, and in the constitution of new transformative discursive formations of the social orders of discourse, in struggle for the institution of new food hegemonies.
\end{abstract}

Keywords: Speech analysis. Discursive practice. Social change. Ideology and hegemony. Food identity.

Recebido em: janeiro 2019

Aceito em: abril 2019

\footnotetext{
1 Doutor em Ciências da Comunicação pela ECA/USP, com Pós-doutorado e Mestrado em Comunicação e Práticas de Consumo (CNPq/ /PPGCOM-ESPM). Professor Colaborador do Mestrado Profissional em Gestão de Alimentos e Bebidas (UAM). Professor e pesquisador da Universidade Anhembi Morumbi (UAM) e da ESPM. Membro da Rede Latinoamericana de Pesquisadores de Cultura Alimentaria, Conocimiento Local y Comunicación. helio@hortica.com.br

2 Mestre em Gestão Profissional de Alimentos e Bebidas pela Universidade Anhembi Morumbi (UAM). Graduada em Administração de Empresas e Pós-graduada em Administração Escolar e Coordenação Pedagógica. Professora da Escola Técnica Getúlio Vargas (ETEC GV). elaperline@gmail.com
} 


\section{DOI: $\underline{10.26512 / l e s . v 20 i 2.21772}$}

\section{INTRODUÇÃO}

O presente artigo busca a reconstrução da conceituação sócio-histórica das chamadas Plantas Alimentícias Não Convencionais (PANC), para, a partir dela, discutir os processos pelos quais mudanças significativas na ordem do discurso social a respeito dos benefícios da produção e consumo desses vegetais tornaram-se reveladoras das lutas contra a padronização hegemônica e globalizada imposta aos hábitos alimentares pela agricultura capitalista de larga escala e pelas grandes plataformas de distribuição atacadista e varejista dos gêneros alimentícios. Alinhamo-nos à Fairclough (2008, p. 91), que considera que o discurso, para além de ser uma forma de representação, constitui-se também em "um modo de ação, uma forma em que as pessoas podem agir sobre o mundo e especialmente sobre os outros".

Da discussão sobre as relações intrínsecas e inextricáveis entre comida e cultura e a respeito do gosto nas práticas alimentares, a pesquisa passa à discussão dos deslocamentos discursivos constatados em um corpus construído por um conjunto amplo e diversificado de textos midiáticos de diferentes gêneros de discurso produzidos, postos em circulação e consumidos na cultura brasileira entres os anos de 2014 e 2018. Ao final, a análise aponta para alterações significativas na lexicalização dos termos relacionados à produção e consumo das PANC, evidenciando mudanças nos padrões hegemônicos da existência social cotidiana. Lembramos com Fairclough (2008, p.105), que "as estruturações particulares das relações entre as palavras e das relações entre os sentidos de uma palavra são também formas de hegemonia". Assim, transpassando os limites porosos entre as culturas das diferentes classes sociais, os sentidos e significados atribuídos a esses alimentos não tradicionais (PANC) passam a constituir novas formações discursivas, que alteram as ordens sociais do discurso, na busca por instituir novas hegemonias alimentares.

\section{PANC: CONCEITO E PRESENÇA NO BRASIL CONTEMPORÂNEO}

Podem ser consideradas PANC as plantas comestíveis, ou partes delas, produzidas, distribuídas e comercializadas fora dos sistemas e circuitos tradicionais de produção e circulação de alimentos, como a agricultura de larga escala e as grandes plataformas de distribuição atacadistas e varejistas. Podem ser plantas nativas ou exóticas adaptadas, silvestres ou espontâneas (KINUPP; LORENZI, 2014). O acrônimo incorpora e expande os seus conceitos para as "Partes Alimentícias Não Convencionais" de gêneros tradicionais, como pecíolos, talos, cascas, sementes, folhas, látex e raízes normalmente desprezadas no preparo das refeições e, ainda, estágios de maturação não usais 
para o consumo como, por exemplo, diferentes frutas verdes (banana, jaca, manga e outras).No senso comum, expresso na linguagem popular cotidiana, tais espécies costumam ser designadas por palavras ou lexias depreciativas como: mato, plantas do mato, invasoras, ervas daninhas, plantas nocivas, pragas, inços. Equivocadamente, são tratadas genericamente como produtos orgânicos, o que não necessariamente são. Para o Ministério da Agricultura, Pecuária e Abastecimento, as PANC são:

aquelas que não receberam ainda a devida atenção por parte da comunidade técnicocientífica e da sociedade como um todo, resultando em consumo restrito a algumas localidades ou regiões, com dificuldade de penetração nas demais áreas do país. Além disso, são culturas que não estão organizadas enquanto cadeia produtiva propriamente dita, não despertando o interesse por parte de empresas de sementes, fertilizantes ou agroquímicos (BRASIL, 2010, p.9)

No panorama internacional, o pesquisador alemão Günter Kunkel (1984) foi um dos pioneiros na catalogação de plantas não tradicionais para o consumo, mas com potencial alimentar, tendo arrolado, com essa perspectiva, cerca de 12,5 mil espécies em todo o mundo. Atualmente, estima-se como alimentícias cerca de $10 \%$ do total das cerca de 300 mil espécies conhecidas em todo o mundo (KNUPP; LORENZI, 2014).

No Brasil, as PANC vêm adquirindo notável centralidade discursiva e forte apelo midiático, especialmente a partir do ano de 2014, com o lançamento do livro "Plantas Alimentícias Não Convencionais (Panc) no Brasil", de autoria do biólogo Valdely Kinupp em parceria com o engenheiro agrônomo Harri Lorenzi, pelo Instituto Plantarum de Nova Odessa (SP). Neste livro, os autores registraram informações botânicas, nutricionais e culinárias sobre 351 espécies comestíveis, que classificaram como alimentos não tradicionais. Além da publicação deste e de outros livros, livretos, manuais, artigos e abundantes matérias jornalísticas sobre o tema, elas têm sido, também, foco principal de programas gastronômicos na televisão, de feiras de negócios e diferentes categorias de eventos distribuídos por todo o País. Vale destacar, ainda, que esses vegetais se tornaram centro de atenção das chamadas expedições botânicas urbanas com propósitos culinários, seguindo tendência observada na gastronomia internacional, cuja expressão original na língua inglesa é foraging, sendo o agente praticante da modalidade denominado forager (IRVING, 2009).

Observa-se que, em torno desses vegetais, ou de suas partes, vem se instarando um conjunto de discursos, que gradativamente se revelam impregnados de sentidos e valores não apenas afetos aos campos semânticos da alimentação e da nutrição, mas também aos das esferas contemporâneas da estética, da política, da ideologia e da ética. Nestas novas práticas discursivas, mais do que prover ingredientes e nutrientes alternativos para as dietas, o uso alimentício das PANC, passou a exercitar olhares e ações de engajamento ativo em prol da defesa da biodiversidade e da orientação para a 
construção social de mercados mais justos, equanimes, saudáveis e sustentáveis. Instaura-se, desta perspectiva, uma crítica mais contundente às grandes redes de distribuição alimentar e seus respectivos papeis sociais na homogeneização dos hábitos alimentares e também às modernas técnicas produtivas das cadeias de suprimento de gêneros, associadas ao uso intenso e inseguro de insumos químicos e organismos geneticamente modificados (OGM), à perda da biodiversidade e à exploração desmesurada dos recursos naturais não renováveis (CASTRO, 2017; ESTEVE, 2017).

Neste contexto, a instauração e a circulação dos discursos sobre as PANC produzem o agenciamento, a valorização e a exposição social de agentes dos chamados circuitos curtos ou subalternos de produção e distribuição de alimentos (JUNQUEIRA, 2018) - pequenos produtores familiares, mateiros, raizeiros, benzedeiras, cozinheiras de populações tradicionais sertanejas, indígenas e quilombolas - e, desta forma, recolocam, na agenda de discussão pública, fenômenos como proteção à biodiversidade, mitigação do êxodo rural e dos riscos das perdas irreversíveis, por ausência de sucessores, na transmissão intergeracional dos saberes e fazeres das populações tradicionais. Consideramos, como Fairclough (2008, p. 105), que "os sentidos das palavras entram em disputa dentro de lutas sociais mais amplas".

\section{O CORPUS DA PESQUISA}

Para a realização dessa pesquisa elegemos um corpus constituído por matérias publicadas em jornais diários e revistas mensais de grande circulação, eleitos entre os principais veículos que têm como foco editorial assuntos ligados à alimentação, gastronomia e divulgação científica em linguagem popular. Foram considerados, ainda, livros, livretos, compêndios de receitas, guias e manuais instrucionais. A coleta abrangeu o período de maio de 2014 a junho de 2018 e seguiu os princípios da relevância e da homogeneidade discursiva e textual, conforme propostos por Barthes (1971), priorizando a experiência o conhecimento prévio dos pesquisadores na seleção dos materiais considerados pertinentes aos propósitos da investigação. Descartados os materiais meramente descritivos das plantas ou de receitas e aqueles que apenas continham informações ou textos repetidos ou copiados de outras fontes principais, sem acréscimos relevantes, resultou um conjunto de 15 textos integrais, cuja classificação, segundo gênero discursivo, suporte ou meio de divulgação empregado é mostrado no Quadro 1 seguinte. Sobre o conjunto textual assim obtido e selecionado, aplicaram-se, para a interpretação dos processos da construção social dos sentidos, os princípios teóricometodológicos da Análise do Discurso em seus desdobramentos e conexões com a mudança social (FAIRCLOUGH, 2008). 
Os excertos extraídos do corpus de pesquisa são arrolados ao longo da análise empreendida, sempre citados entre aspas, mantendo-se a sua grafia original. Todos os grifos sobre esses extratos textuais são nossos, visando destacar os sentidos expostos eleitos para a análise discursiva.

Quadro 1 - Corpus da pesquisa, segundo gênero discursivo e suportes ou meio de circulação, 20172018.

\begin{tabular}{|c|c|c|c|}
\hline \multicolumn{2}{|r|}{ Gênero discursivo } & Suportes ou meios & Corpus \\
\hline \multirow{3}{*}{ 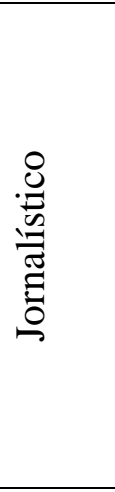 } & Reportagem & $\begin{array}{l}\text { Jornal diário } \\
\text { O Estado de São Paulo } \\
\text { Suplemento Paladar }\end{array}$ & $\begin{array}{l}\text { Boni (2018); Mesquita } \\
\text { (2017); Prado (2017); } \\
\text { Smeraldi (2017); Tucci } \\
\text { (2018). }\end{array}$ \\
\hline & Crítica gastronômica & $\begin{array}{l}\text { Revistas mensais } \\
\text { Prazeres da Mesa } \\
\text { JCultura[ }\end{array}$ & $\begin{array}{l}\text { Campos (2018); Manso } \\
\text { (2018). } \\
\text { Tucci (2018). }\end{array}$ \\
\hline & Divulgação científica popular & $\begin{array}{l}\text { Revista mensal } \\
\text { Superinteressante }\end{array}$ & Rogov (2017). \\
\hline \multirow{3}{*}{ 它 } & Acadêmico & Livro & Kinupp; Lorenzi (2014). \\
\hline & Manuais e guias & Livretos e brochuras & $\begin{array}{l}\text { Brasil (2010); Embrapa } \\
\text { (2017); Ranieri (2017). }\end{array}$ \\
\hline & Receitas culinárias & Compêndio & São Paulo (2017). \\
\hline 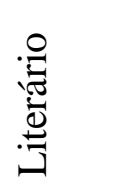 & Crônica & $\begin{array}{l}\text { Jornal diário } \\
\text { O Estado de São Paulo } \\
\text { Suplemento Paladar }\end{array}$ & Reinach (2017). \\
\hline
\end{tabular}

Fonte: elaborado pelos autores

\section{DisCUSSÃo}

O discurso se constrói em profundo diálogo com a cultura, tecendo tramas de sentidos intralinguísticos, a partir de relações extralinguísticas que ele reflete, refrata e revela. As redes de sentidos que se estabelecem no discurso podem ser estudadas à luz dos conceitos de campo associativo das palavras e lexias que os enunciados mobilizam e agenciam (ULMANN, 1973). Tratase, nesse percurso analítico, da possibilidade de focalizar a reflexão na relação dialética que se instaura entre as estruturas e elementos propriamente linguísticos e as injunções socio-históricas, políticas e culturais constituintes da temporalidade do discurso (ORLANDI, 1990). Ou seja, da habilidade de se tecer conexões significativas entre "signo e ideologia, palavra e poder, linguagem e experiências culturais" (BACCEGA; CITELLI, 1989, p. 28). A linguagem - para muito além de viabilizar fluxos de informações - estabele relações, vínculos, ordens, hierarquias, inclusões e exclusões sociais. Assim, a análise crítica dos usos dos recursos da linguagem e dos discursos deve 
priorizar os embates dos enunciados com a realidade-mundo, nos quais os sentidos de confrontam e se conformam. Para Fairclough (2008, p. 99),

a análise de um discurso particular como prática discursiva, focaliza os processos de produção, distribuição e consumo textual. Todos esses processos são sociais e exigem referência aos ambientes econômicos, políticos e institucionais particulares nos quais o discurso é gerado.

A observação de novas práticas sociais e das alterações na ordem do discurso sobre as PANC no corpus analisado permitiram a identificação crítica de diferentes dimensões socioculturais ligadas ao cenário gastronômico brasileiro contemporâneo, em seus movimentos de transformação, entre as quais destacamos as seguintes: i) o enobrecimento simbólico e cultural dessas plantas; ii) a espetacularização social das PANC a partir da sua apropriação pelo mercado gourmet; iii) o "resgate" histórico e cultural de saberes e fazeres culinários tradicionais; iv) a ludicidade, a sensorialidade e o sabor associados ao consumo desses vegetais não tradicionais, e v) a representação social da sustentabilidade, da ética e do engajamento ativo de consumidores na construção social dos mercados. Nos tópicos que se seguem, cada um desses temas será apresentado e discutido individualizadamente.

\section{COMIDA E CULTURA: SOBRE O GOSTO NAS PRÁTICAS ALIMENTARES}

Comida, alimento e alimentação constituem-se em elementos e práticas sociais de forte conexão com a memória afetiva de grupos e indivíduos. Representam formas de transmissão de culturas, hábitos, tradições, memórias, saberes e fazeres. A comensalidade e o compartilhamento das refeições são práticas que aproximam pessoas e que reforçam e atualizam os laços sociais. (POLLAN, 2013; BARCELLOS, 2017).

Assim, a dieta alimentar é plenamente revestida de caráter ideológico e suas expressões comportam escolhas, dilemas, possibilidades e adaptações que, em suma, refletem as condições materiais e simbólicas da existência dos diferentes grupos sociais ao longo da sua história. Comer constitui-se processo de identificação coletiva, a partir da presença ativa de um conjunto de valores, representações e práticas alimentares compartilhadas no âmbito de uma cultura (CONTRERASHERNANDZ; GRACIA-ANAIZ, 2005; POLLAN, 2006).

$\mathrm{Na}$ contemporaneidade, longe de ter conseguido equacionar adequadamente e resolver os históricos problemas da fome e da desnutrição que assolam grande parte da população do planeta, a humanidade passou a enfrentar novos desafios alimentares, entre os quais se destacam: i) a epidemia da obesidade e das doenças a ela associada (cardiopatias, diabetes e outras); ii) os comportamentos e distúrbios patológicos associados às práticas alimentares (anorexia, bulimia, preocupações e cuidados 
obsessivos com a estética corporal, entre outros) (ROSSI, 2013); iii) a proliferação das dietas restritivas ou livres de determinados componentes (light/diet, sem glúten, sem lactose, sem cafeína etc.); iv) a espetacularização da alimentação gourmet; v) o medo, a perda de confiança e a rejeição dos produtos superprocessados, que configuram a chamada "angústia alimentar" (BECK, 2010), vi) a identificação e a valorização dos territórios de origem (terroir) e do locavorismo (RUDY, 2012) ${ }^{3}$, e vii) a consolidação de movimentos do ativismo alimentar (agricultura orgânica, vegetarianismo, veganismo etc.) (VILELA, 2017). Significa dizer que, aos problemas históricos da carência, vieram se sobrepor dilemas e desafios originários da abundância alimentar.

Nesse novo contexto, passa a predominar a exigência da qualificação cultural do consumidor, necessária para que ele possa proceder às suas escolhas frente a uma oferta cada vez mais farta, diversificada e persuasiva de opções alimentares. Os apelos não são mais só quanto ao que se come, mas também em relação ao por quê, onde e quando se come e com quem se partilha comida, haja vista a proliferação da oferta de novos tipos de alimentos e modalidades de pontos e situações de consumo. O sujeito contemporâneo torna-se, assim, eclético e flexível em relação à comida, em todas as suas dimensões: obtenção, preparo, conservação, consumo, partilha e eventualmente descarte de partes e de restos alimentares. Se por um lado, os hábitos arraigados, os formalismos e os tradicionalismos alimentares são desritualizados, por outro, novas demandas vêm se impor, instituindo novas socialidades, preferências e identidades (ASCHER, 2005).

Ao eleger, o consumidor constrói, reconstrói, descobre, reafirma e expressa não apenas seu gosto, mas também a sua identidade como sujeito. Para Poulain (2009, 2012), configura-se, na contemporaneidade, o que ele denomina de um "espaço social alimentar", que reflete um novo estatuto adquirido pela alimentação, no qual novos modelos alimentares buscam espelhar preocupações, aspirações e engajamentos, a partir de critérios atribuíveis aos alimentos. Escolher para além dos valores de ordem médica, nutricional e estética - incorpora e considera, também, predicados sociais, ideológicos e morais. Desta forma, sobre os alimentos passam a pesar demandas polivalentes. Eles necessitam ser, ao mesmo tempo: seguros, limpos, saborosos, saudáveis, práticos, convenientes, funcionais, nutritivos, eficazes e sustentáveis. Devem agregar valores materiais e simbólicos, da esfera tanto do corpo, quanto da mente e do espírito e serem simbolicamente significativos nos âmbitos tanto individual quanto social. Afirma Gomes (2018):

O consumo de hortaliças não convencionais é importante para a diversidade e riqueza da dieta alimentar e o fomento aos bons hábitos alimentares [...]. Esses alimentos são considerados um patrimônio a ser conservado e preservado [...]. A melhor maneira de preservar essas espécies e impedir o seu desaparecimento é com

\footnotetext{
${ }^{3}$ Locavore é um termo cunhado na língua inglesa para designar consumidores interessados na compra e consumo de alimentos produzidos localmente. Foi cunhada por Jessica Prentice, nos EUA (RUDY, 2012).
} 
a própria utilização dessas plantas. [...] A Embrapa realiza um trabalho de manutenção e de resgate daquelas hortaliças que eram utilizadas no passado e que foram caindo em desuso em função das mudanças no padrão da sociedade brasileira, com a globalização, urbanização verticalizada e perda das referências dos quintais produtivos

O surgimento do conceito de cultura culinária como elemento estruturante da gastronomia burguesa, enquanto ato público, encontra sua expressão socio-histórica no livro "The physiology of taste", de Brillat-Savarin, publicado originalmente na França, no ano de 1825. Nele, o autor discute e propõe o ato de alimentar-se como uma nova atitude do sujeito diante do mundo, a partir da qual este se vale de critérios materiais e simbólicos para eleger o "melhor" entre os gêneros disponíveis, assim como as formas adequadas de prepará-los e consumi-los (BRILLAT-SAVARIN, 2011). Seus pressupostos baseiam-se decisivamente no hedonismo e no gosto como expressão da distinção social, tema posterior e densamente tratado por Bourdieu (2007).

A formação do gosto é um processo social e simbólico, que diz simultaneamente respeito à constituição identitária de si e à diferenciação em relação ao Outro. Decorre da instituição do enraizamento e do pertencimento do indivíduo ao seu grupo social e à sua cultura. A comida é um código, que expressa valores, sentidos, mensagens, relações, hierarquias e acontecimento sociais (DOUGLAS; ISHERWOOD, 2004). Transmite, ainda, sinalizações simbólicas a respeito de interdições, tabus, limites, purezas, riscos, permissões e transgressões de ordem religiosa, ética, moral ou estética (DOUGLAS, 2014). A formação do gosto compõem-se, ao mesmo tempo, de fundamentos genético-evolutivos e de elementos culturais. Mássimo Montanari (2008, p. 11), destacado historiador da alimentação destaca que "o gosto é um produto cultural resultante de uma realidade coletiva e partilhável, em que as predileções e as excelências destacam-se não de um suposto instinto sensorial da língua, mas de uma complexa construção histórica”.

\section{DE "MATO" A ALIMENTO: TRAJETÓRIAS DE ENOBRECIMENTO SOCIAL DE PLANTAS}

Do ponto de vista antropológico, os processos de escolha das espécies que podem servir ou não de alimento são complexos e revestidos de valores sociais e simbólicos, mais do que puramente utilitários ou biológicos. Levi-Strauss (1973, p. 172) registrou que "as espécies naturais não são escolhidas por serem 'boas para comer', mas por serem 'boas para pensar'”, atestando a carga múltipla de significados carreados pelos itens e atos alimentares, em cada grupo social.

Cabe destacar, contudo, que ao longo da História das funções socioeconômicas e culturais das trocas e intercâmbios comerciais entre os povos, o utilitarismo no conhecimento e exploração da natureza teve primazia e pautou, de maneira especial, as relações das conquistas coloniais. Neste 
contexto, o costume ancestral de classificar os vegetais em plantas "úteis" e "mato", decorreu das tradições taxonômicas iluministas, do século XVIII, expressas no conceito de "economia da natureza", conforme proposto por Lineu e documentado em obra assinada por seu discípulo Biberg, em 1749 (PRESTES, 2000):

Tudo o que se apresenta aos nossos sentidos, tudo o que se apresenta ao nosso espírito e merece ser observado, concorre, por sua disposição própria, a manifestar a glória de Deus, isto é, a produzir a finalidade que Deus concebeu como propósito último de todas as suas obras (LINNÉ, 1972, p. 58, grifos nossos).

Assim, as plantas - e os seres vivos, em geral - são entendidos a partir da ótica de sua destinação a expressar uma função, um propósito, uma finalidade última, motivos de sua criação e existência no mundo. A Botânica, desta forma, surge definida pela Agricultura, enquanto ciência focada na exploração das utilidades dos entes naturais.

No Brasil, tais práticas aportaram com as tradições mercantilistas-colonialistas portuguesas que conformaram, em sua origem, a essência do caráter nacional. A partir das práticas de dominação aqui implantadas, introduziram-se no País centenas de espécies consideradas úteis já aclimatadas em Portugal, em suas ilhas atlânticas ou em outras colônias. Ao mesmo tempo, o colonizador empreendedor buscou conhecer e inventariar, no Brasil, as plantas nativas que apresentavam algum nível de interesse econômico potencial. E tão somente essas. Os focos concentraram-se, então, nos vegetais capazes de oferecer alimentos e nutrição para homens e animais, remédios ou princípios medicinais aromáticos e condimentares (as ditas “drogas do sertão"), fibras, madeiras para a construção e a navegação e materiais tintoriais diversos (DEAN, 1991). Excepcionalmente, no campo do comércio de espécies ornamentais, as orquídeas brasileiras ganharam algum destaque na economia da época, embora ao custo da destruição de quantidades incomensuráveis de matas e florestas. As demais espécies, que não se enquadraram em nenhuma dessas categorias apontadas, foram simplesmente desprezadas e denominadas, desde então, "mato", "praga" ou "inço", operação linguística que, ao mesmo tempo, lhes "retirava a substância e lhes designava um status quo" (BACCEGA, 2007, p. 49), pois que “as práticas discursivas são formas materiais de ideologia (FAIRCLOUGH, 2008, p. 116).

Ao longo da História e das múltiplas miscigenações culturais, a classificação dos vegetais em "úteis" e "mato" sofreram alterações. No entanto, esse movimento não alterou a rota da concentração alimentar em um número cada vez mais reduzido de espécies. No Brasil, como na maioria dos países ocidentais, 90\% das necessidades calóricas são cobertas por apenas cerca de 20 espécies (KNUPP; LORENZI, 2014). Isso atesta que o que veio, de fato, a prevalecer e a se impor sobre outras perspectivas de natureza antropológica e cultural, foram as diretrizes econômicas ditadas 
pela agricultura empresarial de grande porte, pelo processamento agroindustrial massivo e pela distribuição industrial em largas plataformas comerciais de atacado e varejo (CASTRO, 2017; ESTEVE, 2017).

Contudo, na contemporaneidade esse modelo hegemônico vem, gradativamente, expondo suas brechas e rachaduras, deixando entrever suas mazelas e perversões e instigando o surgimento de releituras e reconfigurações de práticas alimentares que, mais do que investidas de preocupações nutricionais e estéticas, revestem-se de caráter político, ético e moral.

É nesse novo contexto que as PANC passaram a ser intensa e discursivamente reconvertidas de "mato" para alimento, de "comida de pobre" para alimento gourmet, de item da rua, para destaque da casa e da mesa, ocupando uma nova posição nas práticas sociais. Elas vêm sendo, desta forma, ressignificadas, adquirindo novo estatuto, construído a partir de movimentos políticos de resistência e de revalorização de práticas e culturas contra-hegemônicas. Vejam-se os seguintes excertos coletados: "parece mato, inço ou erva daninha, mas é de comer" (FUTURA, 2016), "aquela plantinha dispersa no meio do jardim, ou do mato, é fonte nutricional" (GOMES, 2018); "qualquer mato que a gente despreza é uma PANC em potencial, se não for tóxica” (ROGOV, 2017, p. 42);“que matinho é esse?" (BREVES, 2016).

Aqui, a construção linguística da nova representação social pretendida, incorpora e explicita os elementos do confronto que lhe entranha: "espécies de planta até ontem consideradas daninhas" (ROGOV, 2017, p. 42); "são chamadas de não convencionais porque crescem como mato e não ganham a atenção da indústria" (BONI, 2017, p. D3); "dificilmente são achadas em mercados" (BONI, 2017, p. D3); “São espécies restritas a determinadas regiões, sua distribuição é limitada e não têm uma cadeia produtiva estabelecida, ou seja, não despertam interesse comercial em empresas de sementes ou de fertilizantes" (GOMES, 2018).

Vê-se, pois, que o reconhecimento do fato de essas plantas não terem despertado o interesse da indústria e de não serem encontradas nos mercados são elementos que atestam sua identidade marginal frente às lógicas contemporâneas da massificação e da homogeneização alimentar, ao mesmo tempo em que lhe lhe asseguram pertencimento ao rol dos produtos simbólicos na reconfiguração de práticas alimentares mais adequadas aos novos anseios simbólicos e representacionais dos consumidores. Vejamos no excerto: Parece que, quanto menos a indústria dá bola para um ingrediente ou um sistema de produção, mais chefs e pesquisadores resolvem mergulhar no assunto e reverberá-lo. E assim tem sido com as pancs” (BONI, 2017, p. D2).

Nessa nova formação discursiva, as PANC surgem como solução para o cultivo local de alimentos, a partir da qual o transporte de larga distância, o consumo de combustíveis fósseis e a consequente emissão de poluentes ambientais podem ser fenômenos minimizáveis: “as PANC devem 
estar relacionadas com aquilo que o ambiente local pode proporcionar. O interesse não é importar alimentos de longe, e sim maximizar aquilo que pode ser oferecido em torno de um certo local" (RANIERI, 2017, p. 8).

Nesse contexto, a opção pelo consumo de PANC se configura como proatividade em favor da ação ambientalista e nela se alistam tanto consumidores, quanto chefs e empresários do mundo gastronômico. Discursivamente, desenham-se expectativas de proteção da biodiversidade ameaçada pela agricultura industrial e OGMs, de reconversão das práticas agrícolas tradicionais para outras mais limpas e amigáveis ao meio ambiente e da revalorização e sobrevivência da pequena agricultura familar, das populações e culturas tradicionais. Vejamos os excertos: "ao usá-las, contribuímos para um tipo de agricultura menos nociva" (chef Helena Rizzo em entrevista a BREVES, 2016); “escolher comer PANC é um ato de liberdade e autonomia que aumenta a biodiversidade do seu prato" (chef e colunista gastronômica Helena Rizzo em entrevista a TUCCI, 2018b, p.59); “para o ambiente, produzir uma PANC significa reconhecer espécies nativas cujo uso está desaparecendo e valorizar a nossa biodiversidade, porque muitas delas ainda são subutilizadas como alimento" (RANIERI, 2017, p. 8), e

usar as PANCs é o maior dever dos chefs. Há 80 anos, existiam mais de 490 diferentes tipos de alface pelo mundo. Hoje temos apenas 36. O cenário atual é alarmante. É nossa obrigação trazer novas espécies a fim de diversificar e fortalecer o nosso meio ambiente e o produtor (chef Carlos Cordeiro em entrevista a BREVES, 2016).

\section{DE "COMIDA DE POBRE" A PRODUTO GOURMET}

Há que se destacar que, no Brasil, especialmente nos anos das décadas de 1970 a 1990, as preocupações e atenções para com as PANC já existiam e eram, então, focadas, de maneira praticamente exclusiva, enquanto possibilidade de oferta de itens de suplementação às carências alimentares e nutricionais e/ou ao combate à fome de populações socioeconomicamente marginalizadas, ou seja, à mitigação das condições populares de insegurança alimentar (SÃO PAULO, 1987).

Naquele período, a despeito de terem sido foco de atenção do poder público e tema de inúmeras publicações técnicas (manuais, compêndios de receitas, instruções de cultivo etc.) e de produtos midiáticos (jornais, revistas, programas de rádio e televisão etc.), não lograram obter qualquer forma de sucesso relevante. Pois que, uma vez estabelecido o seu reconhecimento e estatuto social como "comida de pobre", as PANC mantiveram-se (e ainda mantêm-se, em muitas instâncias) alvo de rejeição e desapreço: "Muitos desses ingredientes são vistos como comida de pobre. (ROGOV, 2017, p. 43). 
Assim, há que se ressaltar que a "redescoberta" e revalorização desses vegetais se dão, a partir de meados da década de 2010, em um contexto completamente modificado. Ou seja, como elemento demonstrativo da distinção e do aprimoramento social do gosto (BOURDIEU, 2007) de determinadas parcelas da população de melhores condições socioeconômicas. Em realidade, elas passam a ser publicamente reapresentadas agora não mais por autoridades e técnicos governamentais preocupados com a fome e a desnutrição popular, mas sim por chefs e profissionais do mercado gourmet, revestidos de autoridade e legitimados pela mídia massiva: "de comida de pobre, as Pancs passaram a ganhar prestígio nos últimos anos entre renomados chefs e nutricionistas brasileiros" (FUTURA, 2016); “em agosto de 2016, as PANC debutaram em rede nacional, numa prova de cozinheiros do Masterchef Brasil. Era a síntese do que já borbulhava na imprensa especializada e nas redes sociais" (ROGOV, 2017, p. 43); “somos todos PANCs: as plantas alimentícias não convencionais dão o sabor da gastronomia moderna" (BREVES, 2016).

Constatamos, pois, o movimento de transição e de reaprorpriação transclassista de valores e sentidos atribuídos a esses vegetais, conforme anunciado por Baccega (2007, p. 49) para quem "na palavra está a manifestação do sistema de valores, da ideologia", pois que "numa sociedade de classes, as práticas linguísticas estão plenas de relação de classe". Para ela, "a história está na língua" (BACCEGA, 2007, p.49). Ou, como para Bakhtin ( p. 43) "cada época e cada grupo social têm seu repertório de formas de discurso na comunicação sócio-ideológica”. Assim, ressignificadas, as PANC atravessam o espaço social que separa a rua das casas, privadas ou comerciais, conquistando as mesas mais sofisticadas. Analisemos os excertos seguintes: "Panc de boutique: da rua para a mesa" (TUCCI, 2018b, p. 59); "plantas antes consideradas mato chegam às cozinhas dos melhores restaurantes e viram estrelas das hortas comunitárias" (TUCCI, 2018b, p. 59).

Configura-se aqui, ideologicamente, a alteração social da ordem do discurso, com a transposição das PANC em seus novos campos semânticos para outra formação discursiva, ou seja, daquela da pobreza e da insegurança alimentar das classes populares para a da elite, na busca de reconfigurar nova hegemonia alimentar. Confirmamos, como indicado por Fairclough (2008, p. 123), que aqui "a articulação e a rearticulação de ordens do discurso transformam-se em marco delimitador da luta hegemônica".

\section{RESGATE CULTURAL OU "INVENÇÃO" DE TRADIÇÕES?}

Como temos visto, a análise do corpus da pesquisa revelou múltiplas dimensões simbólicas associadas às PANC no campo da gastronomia brasileira contemporânea. Entre elas, especial destaque é conferido ao discurso do objetivo e da prática do "resgate cultural" que o seu cultivo e 
consumo encetam. Veja-se os seguintes excertos: "Esse olhar encantado com o mundo natural é o resgate de um conhecimento cultural que se perdeu com o tempo" (ROGOV, 2017, p. 43); "Num cenário em que a população brasileira consome cada vez mais alimentos prontos, ultraprocessados, as PANCs podem resgatar a relação das pessoas com o que elas comem - e trazer os nutrientes de volta à mesa" (ROGOV, 2017, p. 43).

Neste contexto, a ideia de "resgate" reveste-se de conteúdos históricos e memorialistas locais, contrapostos à cultura alimentar desenraizada, massiva e industrial, como na fala da sommelière Lis Cereja (PRADO, 2017, p. D5): “queremos resgatar alimentos e tradições perdidas pela produção industrial e extrapolar para a parte sensorial [...] recuperar a conexão com ingredientes, cultura e histórias locais". Outros manifestantes analisados também seguiram na mesma direção: "fazemos um trabalho de manutenção e de resgate daquelas hortaliças que eram utilizadas no passado e que foram caindo em desuso" (GOMES, 2018); "a tendência vem sendo sentida de forma crescente. Há grande procura por ingredientes que, além de artesanais e orgânicos, tenham um lastro histórico" (PRADO, 2017, D5);

muitas plantas estão esquecidas e já não são mais vistas como alimento. Voltar a consumí-las é uma forma de evitar que desapareçam do nosso cotidiano, ajudando a valorizar as culturas alimentares nas quais essas plantas estão presentes. Contribui ainda para aprendermos com os agricultores e todos aqueles que trazem essa sabedoria da roça e de antigamente, como muitos de nossos pais e avós que as utilizavam, embora esse conhecimento esteja se perdendo (RANIERI, 2017, p. 7-8).

No processo discursivo do "resgate cultural" de práticas alimentares ancestrais, surge, se instaura e é valorizada, com centralidade, a dimensão sociocultural dos territórios socioambientais (LEFF, 2016): "ninguém enxergava o não-convencional como um nicho peculiar, mas sim como o universo de uma diversidade formadora do território" (SMERALDI, 2017, p. D1); "a panc da cidade não é a mesma da floresta, a do índio não é a do ribeirinho, a do venezuelano não é a do acreano" (SMERALDI, 2017, p. D1).

a classificação de um vegetal como PANC varia de cultura para cultura. Plantas silvestres de uso regional são PANCs em outros lugares do planeta - ou até na cidade vizinha. O que é hortaliça convencional em São Paulo pode não ser no Ceará ou em Portugal, e vice-versa. A ora-pro-nóbis (Pereskea aculeata), que cresce espontaneamente em pastagens do Sul ao Nordeste, chega à mesa dos mineiros como se fosse couve (ROGOV, 2017, p.43).

Em realidade, há que se ressaltar, conforme já apontado por Junqueira (2018, p. 229), que "a construção simbólica dos territórios alimentares se dá em contextos de disputas entre tradições", ou seja, em processos de orientações seletivas, de rememorações e de esquecimentos, no interior dos 
quais os sujeitos e os coletivos sociais são também interessadamente reinterpretados. Para esse autor (JUNQUEIRA, 2018, p. 230), "assim como as tradições, os territórios são também reinventados com o concurso da força imaginativa, coletiva e dialógica dos imaginários sociais”. Nesse sentido, conforme proposto por Flores (1997), "resgate" ou "recuperação" de fenômenos e elementos de natureza cultural são complexos, senão mesmo inacessíveis, posto que a cultura se constrói, desconstrói e se reconstrói incessantemente, segundo alternâncias e reconfigurações hegemônicas das ordens dos discursos sociais. Nesse sentido, a produção imaginária dos territórios e das práticas alimentares podem ser melhor entendidas sob a perspectiva da "inveção das tradições" (HOBSBAWN; RANGERS, 1984) e dos agenciamentos da memoria e do imaginário social na reconstrução de uma nova ordem do discurso, do que pelo "resgate" ou "recuperação" cultural.

Neste contexto, novas formações discursivas sobre as PANC intencionalmente apagam memórias de carências, pobrezas, injustiças e exclusões sociais - no interior das quais, "comer mato" ou "comida de pobre" avilta, constrange, humilha e atesta o sentido social do fracasso - para recriar, valorizadas e glamurizadas, "lembranças" de um passado bucólico, saudável, natural, cuja recuperação passa a ser desejável. Dessa forma, são “esquecidas”, por exemplo, as referências históricas feitas pelo sociólogo pernambucano Gilberto Freyre, que fartamente documentou o desprezo e ojeriza das elites senhoriais do Brasil colônia a respeito do consumo de vegetais. Para esses senhores de engenho e de terras e para as "gentes nobres dos sobrados": "comer vegetais equivalia a 'comer mato', característica que remetia à população escrava, em contraposição à elite, que sempre deu preferência à alimentação baseada na carne (2000, p. 311). Segundo registra ainda Freyre, “o vegetal, ou o 'mato', com uma exceção ou outra, representava alimento barato $e$ desprezível, da gente de senzala e da de mucambo" (2000, p. 311. Grifos nossos).

No sentido da construção social e simbólica de territórios socio-ambientais, essas "novas tradições" necessitam ser ensinadas e aprendidas. A mídia torna-se importante aliada nessa prática pedagógica que colabora para a difusão de informações e conhecimentos tanto em relação à própria caracterização e reconhecimento das PANC quanto aos usos culinários e propriedades nutricionais dos vegetais incluídos na categoria.

Para Kinupp, a dificuldade em olhar para uma espécie verde e levá-la para a cozinha é a desinformação. É difícil convencer as pessoas a introduzir PANCs na dieta. A maioria acha que urtiga só dá coceira, que picão é mato, que bucha verde é apenas esponja para lavar louça" (ROGOV, 2017, p. 43).

Na prática discursiva cotidiana e na ausência de uma memória social sobre sabores, aromas, texturas e consistências das próprias plantas agora promovidas, a função educativa sobre as PANC recorre aos efeitos da comparação, da imitação ou da paródia, tendo na mira alimentos mais 
conhecidos. Lembremos, com Eni Orlandi (1990, p. 205), que "não paramos de disciplinar o que nos é estranho, mesmo ao preço da caricatura". Assim, as PANC - estranhas, desconhecidas, não tradicionais - são reapresentadas como: "similar à alcachofra" (ROGOV, 2017, p. 43); com "textura que lembra a da maçã, quando está crua, e a do broto de feijão, depois de refogada" (chef Henrique Nunes, do restaurante Naiah, do Instituto Plantarum, Nova Odessa, em entrevista a TUCCI, 2018, p. D1), "um tipo de batata" (TUCCI, 2018, p. D1) ou plantas cujo "pecíolo é suculento e crocante que com ele pode fazer até espaguete" (TUCCI, 2018, p. D1), que "lembram uma endívia” (TUCCI, 2018, p. D1), com sementes “que viram pipoca” (TUCCI, 2018, p. D1)

Não é de se desprezar a constatação de que pelos recursos linguísticos ora midiaticamente mobilizados, as comparações das propriedades organolépticas e culinárias das PANC sincretizam-se com pautas de consumo alimentar das classes sociais mais favorecidas: endívias, alcachofras, maçãs, brotos de feijão, "recheio de tortas e pastéis" (ROGOV, 2017, p.43). E revelam, ainda, o domínio de repertórios culturais e gastronômicos elitizados e globalizados: A "urtiga-brava, aquela que pinica e aparece sem ser convidada entre a grama, vira sopa e cobertura de pizza na Itália e na Escandinávia" (ROGOV, 2017, p.43); “já fizemos um sorbet e um vinagre com a flor do lírio-do-brejo” (chef e colunista gastronômica Helena Rizzo em entrevista a TUCCI, 2018b, p.59); “ingredientes pouco usuais também se misturam às carnes, como no carpaccio com picão-preto" (TUCCI, 2018b, p.5960). Sabemos, conforme proposto por Fairclough (2008, p. 91) que “o discurso contribui para a construção de sistemas de conhecimento e crença”.

\section{LUDICIDADE, SUSTENTABILIDE E ÉTICA NA CONSTRUÇÃO SOCIAL DOS MERCADOS}

Na dimensão da ludicidade no campo da alimentação na sociedade brasileira contemporânea a mudança do discurso sobre as PANC se manifesta especialmente na instituição de programas de coleta urbana coletiva desses alimentos, em excursões monitoradas por especialistas, seguidas do preparo e degustação dos alimentos obtidos (IRVING, 2009), como nos excertos: "a expedição urbana para caçar mato se espalhou por São Paulo" (ROGOV, 2017, p.42); "a gente identificava e colhia pancs durante o dia e, à noite, eu cozinhava com elas" (chef Tati Lund, em entrevista a MANSO, 2018, p. 68-69); “uma vez por mês, um grupo de 12 pessoas sai pelo bairro, com sacolinha na mão, à caça de feijões na calçada e pepininhos em terrenos baldios. No fim do passeio, com duração de três horas, há uma identificação do que foi colhido e um "almoço PANC" (TUCCI, 2018b, p. 60). Os sabores e texturas antes desprezados das PANC por serem considerados "amargos", "azedos", "de gosto ruim", “ásperos", "rígidos", “espinhosos” são transformados agora em novas experiências gustativas repletas do fascínio da descoberta e da surpresa: "variar o cardápio significa, antes de tudo, 
provar coisas novas e se surpreender com os sabores deliciosos que estavam se perdendo. Utilizar plantas não convencionais amplia nosso repertório de gustação e ajuda a criar receitas novas" (RANIEIRI, 2017, p. 8).

Na contemporaneidade, as preocupações dos consumidores com as boas práticas e condições de produção limpa e segura dos alimentos, bem como da proteção da saúde do trabalhador, dos animais e do meio ambiente, têm conduzido à produção e circulação de valores e sentidos éticos, morais e estéticos, que ganham expressão crescente nas escolhas alimentares (SINGER; PETER, 2007). O cenário recente da gastronomia brasileira permeado pela crescente valorização das PANC alinha-se a este contexto internacional, segundo os principais promotores dessa mudança: "Valdely Kinupp acredita que há uma revolução agrícola e gastronômica em curso no Brasil, que o mundo todo acompanha com interesse" (TUCC, 2018B, p. 60). Vejam-se, também, os seguintes excertos: "passamos a consumir só o que a grande indústria e os supermercados nos oferecem, que em geral vem de monocultura, com o uso de agrotóxicos" (chef Neide Rigo, em entrevisa a BONI, 2017, p. D2); “a interação entre diferentes realidades faz nascer vínculos duradouros e traz ressignificação ao ofício rural" (CAMPOS, 2018, p. 20); "participar dessa feira resgatou minha autoestima. O trabalho no campo é sempre de muita luta e aqui somos reconhecidos por ele" (agricultora Hélia Cristina Silva, participante do Mercado da Agricultura Familiar da Ceasa-DF, em entrevista a CAMPOS, 2018, p. 20).

\section{CONSIDERAÇões FinAis}

As ações e práticas discursivas despertadas pela valorização social das PANC e pela mudança do seu estatuto alimentar na sociedade brasileira contemporânea podem, à primeira vista ou em uma análise apressada, parecerem desmesuradas frente ao seu potencial econômico efetivo na dieta alimentar nacional e na reestruturação dos sistemas produtivos e cadeias de suprimento de gêneros alimentícios. Porém, como nos fala Bakhtin (1988, p. 46), "a palavra reflete sutilmente as mais imperceptíveis alterações da existência social”. E é sobre o que apenas resvala pelas fissuras do discurso alimentar hegemônico que nos debruçamos ao longo desta pesquisa. E é na sutil mudança dos sentidos das palavras e lexias, ora aderentes ora flutuantes sobre os significantes, que mobiliza, que conseguimos enxergar novas trilhas possíveis para a mudança social, em direção à uma sociedade economicamente mais justa, socialmente mais inclusiva e ambientalmente mais sustentável. 


\section{REFERÊNCIAS}

ASCHER. F. Le mangeur hypermoderne: une figure de l'individu éclectique. Paris: Odile Jacob, 2005.

BACCEGA, M. A. Palavra e discurso: história e literatura. São Paulo: Ática, 2007.

BACCEGA, M. A.; CITELLI, A. O. Retórica da manipulação: os Sem-Terra nos jornais.

Comunicações e Artes, ano 14, n. 20, p. 23-29, abr. 1989.

BAKHTIN, M. (VOLOCHÍNOV, V. N). Marxismo e filosofia da linguagem. Problemas fundamentais do método sociológico na ciência da linguagem. São Paulo: Hucitec, 1988.

BARCELLOS, G. O banquete da psique: imaginação, cultura e psicologia da alimentação. São Paulo: Vozes, 2017.

BARTHES, R. Elementos de semiologia. São Paulo: Cultrix, 1971.

BECK, Ü. A sociedade do risco: rumo a uma outra modernidade. São Paulo, Editora 34, 2010.

BONI, A. P. Vendem-se PANCS: picão branco, cambará, capuchinha, serralha... O Estado de São Paulo, Suplemento Paladar, n. 599, p. D3, 9 a 15 mar. 2018.

BOURDIEU, P. A distinção: crítica social do julgamento. São Paulo: Edusp, 2007.

BRASIL. Ministério da Agricultura, Pecuária e Abastecimento (MAPA). Manual de hortaliças não convencionais. Brasília: Mapa/ACS, 2010.

BREVES, L. Somos todos Pancs: as plantas não convenciosnais dão o sabor da gastronomia moderna. O Globo, 04 de abril de 2016. Disponível em:

https://oglobo.globo.com/ela/gastronomia/somos-todos-pancs-as-plantas-alimenticias-naoconvencionais-dao-sabor-da-gastronomia-moderna-19436827. Acesso em 13 de maio de 2018.

BRILlAT-SAVARIN, J. A. The Physiology of Taste: Or, Meditations on Transcendental Gastronomy. London: Penguin Books: 2011.

CAMPOS, S. A. Slow Food. Ponto de encontro da biodiversidade. Prazeres da Mesa, ano 15, n. 176, p. 20, abr. 2018.

CASTRO, N. La dictadura de los supermercados. Cómo los grandes distribuidore deciden lo que consumimos. Madrid: Ediciones Akal, 2017.

CONTRERAS-HERNANDEZ, J.; GRACIA-ARNAIZ, M. Alimentación y cultura: perspectivas antropológicas. Barcelona: Ariel. 2005.

DEAN, W. A botânica e a política imperial: a introdução e a domesticação de plantas no Brasil.

Estudos Históricos, v.4, n.8, p. 216-228, 1991.

DOUGLAS, M. Pureza e perigo. São Paulo: Perspectiva, 2014.

DOUGLAS, M.; ISHERWOOD, B. O mundo dos bens: para uma antropologia do consumo. Rio de Janeiro: UFRJ, 2004.

ESTEVE, E. V. O negócio da comida: quem controla nossa alimentação? São Paulo: Expressão Popular, 2017.

FAIRCLOUGH, N. Discurso e mudança social. Brasília: Editora da Universidade de Brasília, 2008.

FLORES, M.B. Oktoberfest - turismo, festa e cultura na estação do chopp. Florianópolis: Letras Contemporâneas, 1997. 
FREYRE, G. Sobrados e mucambos. Rio de Janeiro: Record, 2000.

FUTURA. O que são pancs? Disponível em: http://futura.org.br/trilhas-do-conhecimento/o-quesao-pancs/. Acesso em 1 de maio de 2018.

GOMES, M. Embrapa estuda hortaliças não convencionais e de alto potencial. Correio Braziliense, 30 de abril de 2018. Disponível em:

https://www.correiobraziliense.com.br/app/noticia/economia/2018/04/30/internas_economia,67719 7/ Acesso em: 13 de maio de 2018.

HOBSBAWN, E.J.; RANGERS, T. A invenção das tradições. Rio de Janeiro: Paz e Terra, 1984.

IRVING, M. The Forager Handbook: a guide to the edible plants of Britain. London: Ebury Press, 2009.

JUNQUEIRA, A. H. Territórios alimentares e reinvenção das tradições na cozinha colonial da Serra Catarinense (SC): a experiência da Associação de Agroturismo Acolhida na Colônia. Geografares, p. 216-236, jan./jun.2018.

KINUPP, V.; LORENZI, H. Plantas alimentícias não convencionais (PANC) no Brasil. Nova Odessa, SP: Instituto Plantarum, 2014.

KUNKEL, G. Plants for human consumption. Koenigsten: Koeltz Scientific Books, 1984.

LEFF, E. A aposta pela vida: imaginação sociológica e imaginários sociais nos territórios ambientais do Sul. Petrópolis, RJ: Vozes, 2016.

LEVI-STRAUSS, C. Totemismo hoje. Petrópolis: Editora Vozes, 1973.

LINNÉ, C. v. L'équilibre de la nature: discours sur l'acooissement de la terre habitable (1744), L'économie de la Nature (1749), La police de la nature (1760). Paris: Vrin, 1972.

MANSO, Ú. A. Democracia vegetariana. Tati Lund cozinha com plantas alimentícias não convencionais no Mesa ao Vivo Rio. Prazeres da Mesa, ano 15, n. ${ }^{\circ}$ 174, p. 68-69, fev. 2018.

MESQUITA, R. Você já ouviu falar em Pancs? Neide Rigo explica. O Estado de São Paulo, Paladar, p. D1, 4 a 10 de agosto de 2016.

MONTANARI, M. Comida como cultura. São Paulo: Editora Senac, 2008.

ORLANDI, E. P. Análise do discurso: princípios e procedimentos. Campinas, SP: Pontes, 2003.

ORLANDI, E. P. Terra à vista - discurso do confronto: velho e novo mundo. São Paulo: Cortez; Campinas, SP; Editora da Unicamp, 1990.

POLLAN, M. Cooked: A Natural History of Transformation. New York: Penguin Books, 2013.

POLLAN, M. The Omnivore's Dilemma: a natural history of four meals. New York: Penguin Press, 2006.

POULAIN, J. P. (Coord.). Dictionnaire des cultures alimentaires. Paris: PUF, 2012.

POULAIN, J. P. Sociologie de l'alimentation. Paris: PUF, 2009.

PRADO, M. Evento propõe pensar comida além do prato. O Estado de São Paulo, Suplemento Paladar, n. ${ }^{\circ}$ 629, D5, 5 a 11 de outubro de 2017.

PRESTES, M. E. B. A investigação da natureza no Brasil colônia. São Paulo: Annablume: Fapesp, 2000.

RANIERI, G. R. (Org.). Guia prático sobre PANCs: plantas alimentícias não convencionais. São Paulo: Instituto Kairós, 2017. 
REINACH, F. Comer para preservar. O Estado de São Paulo, Metrópole, p. A25, 2 de set. 2017. ROGOV, B. Mato de comer. Super Interessante, n. ${ }^{\circ}$ 380, p. 38-43, outubro de 2017.

ROSSI, P. Comer: necesidad, deseo, obsesión. Buenos Aires: Fondo de Cultura Económica, 2013.

RUDY, K. Locavores, feminism, and the question of meat. The Journal of American Culture, v.35, n.1, p. 26-36, 2012.

SÃO PAULO. Governo do Estado. A batalha da alimentação no governo Montoro. São Paulo: PW, 1987.

SINGER, P.; MASON, J. A ética da alimentação: como nossos hábitos alimentares influenciam o meio ambiente e o nosso bem-estar. Rio de Janeiro: Elsevier, 2007.

SMERALDI, R. O momento é PANC. O Estado de São Paulo, Suplemento Paladar, p. D1, 20 a 26 de abril de 2017.

TUCCI, N. Beleza que põe mesa. O Estado de São Paulo, Suplemento Paladar, n. ${ }^{\circ}$ 663, p. D1, 24 a 30 de maio de 2018a.

TUCCI, N. Panc de boutique: da rua para a mesa. Cultura, São Paulo, Livraria Cultura/Fnac, n. 1, p. 59-61, jun. 2018b.

ULMANN, S. Semântica: uma introdução à ciência do significado. Lisboa: Calouste Gulbenkian, 1973.

VILELA, D. B. L. Consumo político e ativismo vegano: dilemas da politização do consumo na vida cotidiana. Estudos Sociedade e Agricultura, v. 25, n. 2, p. 353-377, jun. 2017. 